\title{
Responses to constant work exercise in patients with chronic heart failure
}

\author{
N M Picozzi, A L Clark, K A Lindsay, G P McCann, W S Hillis
}

\begin{abstract}
Objective-To describe the kinetics of metabolic gas exchange at the onset and offset of low level, constant work exercise in patients with chronic heart failure. Setting-Tertiary referral centre for cardiology.

Patients-10 patients with chronic heart failure and 10 age matched controls.

Methods-Each subject undertook maximum incremental exercise testing with metabolic gas exchange measurements, and a fixed load exercise test at 25 watts with metabolic gas exchange measurements before, during, and after the test. A monoexponential curve was fitted to the data to describe the kinetics of gas exchange at onset and offset of fixed load exercise.
\end{abstract}

Outcome measures-Peak oxygen consumption; time constants of onset and offset for metabolic gas exchange variables during constant load exercise.

Results-Peak oxygen consumption (mean (SD)) was higher in controls (26.1 (4.3) $v 15.3(5.3) \mathrm{ml} / \mathrm{kg} / \mathrm{min}$; $\mathrm{p}<0.001)$ than in heart failure patients. Oxygen consumption during steady state was the same in both groups $(9.2(1.8) \mathrm{ml} / \mathrm{kg} / \mathrm{min}$ in controls $v 8.6(1.6)$ in patients). The time constant of onset was the same in each group, but the time constant of offset was longer in patients $(1.29(0.14) v 0.82$ $(0.07) ; \mathrm{p}<0.005)$. There was a relation between peak oxygen consumption and time constant of offset $\quad(R=0.56$; p $<0.001$ ).

Department of Medicine and Therapeutics, Glasgow University, Western Infirmary, Dumbarton Road, Glasgow

G11 6NT, UK

N M Picozzi

G P McCann

W S Hillis

Department of

Mathematics, Glasgow

University

K A Lindsay

Department of

Cardiology, Western

Infirmary, Glasgow

A L Clark

Correspondence to:

Dr Clark.

Accepted for publication 7 May 1999 change at the onset of low level exercise are normal in heart failure, but the recovery is delayed. The delay is related to the reduction in exercise capacity. A patient may spend a greater portion of the day recovering from exercise, and may not begin the next bout from a position of true recovery, perhaps contributing to the sensation of fatigue.

(Heart 1999;82:482-485)

Keywords: chronic heart failure; metabolic gas exchange; constant load exercise

The syndrome of chronic heart failure is characterised by reduced exercise capacity, as reflected in a reduction in peak oxygen consumption $\left(\dot{\mathrm{V}}_{2}\right)$ on an incremental exercise test, and an increase in the ventilatory response to exercise, characterised by an increase in the ventilatory equivalent for carbon dioxide.
These exercise abnormalities may be related to abnormal skeletal muscle behaviour. ${ }^{1}$

Steady state exercise at a fixed work load elicits the same oxygen consumption $/ \mathrm{kg}$ whether a patient has heart failure or not. The pattern of increase in oxygen consumption to a plateau when a fixed load is applied can be described by a monoexponential equation, as can the pattern of recovery to resting values at the end of exercise. As it takes a finite time for the circulation to adjust to the exercise load, there is a gap between oxygen demand at the onset of exercise, and the matching of demand to supply in the plateau phase (fig 1). This is known as the oxygen deficit. The pay back at the end of exercise is the relative excess oxygen consumption during recovery. This is the oxygen debt. ${ }^{2}$

Previous investigators have examined the onset $^{34}$ and offset ${ }^{56}$ of exercise, and found a slower rate of adjustment in patients with heart failure, but have not investigated the behaviour of metabolic gas exchange variables at the onset and offset of fixed load exercise in patients with heart failure. This is the aim of the present study.

\section{Methods}

Ethics approval was granted by the local ethics committee, and all subjects gave their informed, signed consent before participating in the study. Ten patients with chronic stable heart failure and 10 age matched controls were studied. No patient had myocardial infarction or an episode of decompensation of their heart failure in the three months preceding the study. Patients with peripheral neuropathy or other locomotor disease or pulmonary disease were excluded from study. All patients


Time

Figure 1 The relation between oxygen deficit and debt shown schematically. At the onset of steady state exercise, oxygen consumption increases in an exponential fashion to reach a plateau. The gap between the eventual plateau and the level seen during the incremental period is the oxygen deficit. The oxygen debt is the oxygen consumption in excess of the baseline levels immediately at the end of exercise. 
Table 1 Subject characteristics

\begin{tabular}{llll}
\hline & Patients $(n=10)$ & Controls $(n=10)$ & $95 \% C I$ \\
\hline Age $($ years $)$ & $60.2(8.7)$ & $56.6(9.0)$ & -4.8 to 12.1 \\
Height $(\mathrm{cm})$ & $171(11)$ & $172(7)$ & -10.4 to 8.7 \\
Weight $(\mathrm{kg})$ & $78.2(14.9)$ & $80.7(16.4)$ & -17.3 to 12.2 \\
Sex $(\mathrm{M}: \mathrm{F})$ & $9: 1$ & $9: 1$ & \\
Peak $\dot{\mathrm{V}} \mathrm{o}_{2}(\mathrm{ml} / \mathrm{kg} / \mathrm{min})$ & $15.3(5.3)$ & $26.1(4.3)^{\star \star \star}$ & -15.4 to -6.2 \\
Exercise time $(\mathrm{s})$ & $403(178)$ & $753(145)^{\star \star \star}$ & -507 to -193 \\
Anaerobic threshold $(\mathrm{ml} / \mathrm{kg} / \mathrm{min})$ & $12.4(4.2)$ & $21.8(4.4)^{\star \star \star}$ & -13.7 to -5.0 \\
Peak RER & $1.16(0.12)$ & $1.20(0.11)$ & -0.149 to 0.067 \\
LVEDD $(\mathrm{cm})$ & $6.0(1.0)$ & - & - \\
\hline
\end{tabular}

Values are means (SD).

$\star \star \star \star_{\mathrm{p}}<0.001$ for comparison between the two groups.

CI, confidence interval; LVEDD, left ventricular end diastolic dimension from cross sectional echocardiography; $\dot{\mathrm{V}}_{2}$, oxygen consumption; RER, respiratory exchange ratio at peak exercise.

Table 2 Variables for oxygen consumption during steady state exercise

\begin{tabular}{llll}
\hline & Patients $(n=10)$ & Controls $(n=10)$ & $95 \%$ CI \\
\hline Resting $\dot{\mathrm{V}} \mathrm{o}_{2}(\mathrm{ml} / \mathrm{kg} / \mathrm{min})$ & $3.1(0.6)$ & $3.2(0.5)$ & -0.64 to 0.39 \\
Plateau $\dot{\mathrm{V}} \mathrm{o}_{2}(\mathrm{ml} / \mathrm{kg} / \mathrm{min})$ & $8.6(1.6)$ & $9.2(1.8)$ & -2.23 to 1.00 \\
$\tau$ onset & $1.11(0.23)$ & $0.92(0.25)$ & -0.53 to 0.91 \\
$\tau$ offset & $1.29(0.14)$ & $0.82(0.07) \dagger$ & 0.14 to 0.81 \\
$\mathrm{O}_{2}$ deficit $(\mathrm{ml})$ & $6.4(1.5)$ & $6.1(2.1)$ & -5.2 to 5.7 \\
$\mathrm{O}_{2}$ debt $(\mathrm{ml})$ & $7.2(1.0)$ & $5.0(0.6)^{\star}$ & 0.3 to 4.69 \\
\hline
\end{tabular}

Values are mean (SD).

${ }^{\star} \mathrm{p}=0.05, \mathrm{tp}<0.005$ for the comparison of patients with controls

$\mathrm{CI}$, confidence interval; $\tau$, time constant either of offset or onset.

werereceiving angiotensin converting enzyme inhibitors and diuretics. None of the controls was taking regular medication.

Subjects attended on two occasions. Height and weight was measured. On the first occasion, a maximum incremental treadmill exercise test was performed using the Bruce protocol. Expired air was sampled continuously, and metabolic gas exchange measurements were performed (MedGraphics cardiorespiratory diagnostic systems, CardiO2 and CPX/D systems, using BreezeEx software; Medical Graphics Corp, St Paul, Minnesota, USA). The system was calibrated before each test. The ECG was monitored continuously, and blood pressure measured every three minutes.

On the second visit, subjects performed cycle ergometer (EM 840, Siemens, Erlangen, Germany) exercise at a fixed load of 25 watts for 10 minutes. Metabolic gas exchange data were recorded continuously for 10 minutes before and for 10 minutes after the exercise test.

Table 3 Time constants for the onset and offset of exercise for carbon dioxide production $\left(\dot{V} \mathrm{CO}_{2}\right)$ and ventilation $\left(\mathrm{V}_{\mathrm{E}}\right)$

\begin{tabular}{lllll}
\hline & & Patients $(n=10)$ & Controls $(n=10)$ & $95 \% C I$ \\
\hline$\dot{\mathrm{V}} \mathrm{CO}_{2}$ & $\tau$ onset & $1.63(0.81)$ & $1.24(0.90)$ & -0.41 to 1.20 \\
$\mathrm{VE}$ & $\tau$ offset & $1.75(0.58)$ & $1.07(0.36)^{\star \star}$ & 0.23 to 1.14 \\
& $\tau$ onset & $2.18(1.30)$ & $1.35(1.43)$ & -0.45 to 2.12 \\
& $\tau$ offset & $1.87(0.70)$ & $1.19(0.38)^{\star}$ & 0.15 to 1.21
\end{tabular}

Values are mean (SD).

${ }^{\star} \mathrm{p}=0.01 ;{ }^{\star \star} \mathrm{p}<0.01$.

$\mathrm{CI}$, confidence interval.

Table 4 Correlations between time constants of onset and offset

\begin{tabular}{llllll}
\hline & $\mathrm{O}_{2}$ onset & $\mathrm{CO}_{2}$ onset & VE onset & $\mathrm{O}_{2}$ offset & $\mathrm{CO}_{2}$ offset \\
\hline $\mathrm{O}_{2}$ onset & & & & & \\
$\mathrm{CO}_{2}$ onset & 0.84 & & & & \\
$\dot{\mathrm{V}}$ onset & 0.61 & 0.91 & 0.72 & & \\
$\mathrm{O}_{2}$ offset & $\mathbf{0 . 4 3}$ & 0.59 & 0.76 & 0.93 & \multirow{2}{*}{0.93} \\
$\dot{C O}_{2}$ offset & 0.52 & $\mathbf{0 . 6 6}$ & 0.56 & 0.82 & \\
$\dot{\mathrm{V}}$ offset & 0.39 & 0.48 & $\mathbf{0 . 5 6}$ & \\
\hline
\end{tabular}

The direct correlations between onset and offset for each variable are highlighted in bold. $\dot{\mathrm{V}} \mathrm{E}$, expiratory minute volume.
DERIVED VARIABLES

Peak $\dot{\mathrm{V}} \mathrm{O}_{2}$ and the $\dot{\mathrm{V}} / \dot{\mathrm{V}}_{\mathrm{CO}_{2}}$ slope, where $\dot{\mathrm{V}} \mathrm{CO}_{2}$ is the carbon dioxide production and $\dot{V}_{\mathrm{E}}$ is the expiratory minute volume, were derived from the maximum exercise test data. For each of the submaximal tests, a monoexponential curve was fitted to the onset and offset data, and the time constants $(\tau)$ of onset and offset were derived (see appendix). The oxygen deficit was calculated as the difference between resting and plateau $\dot{\mathrm{V}}_{2}$ multiplied by the time constant of onset, and debt was calculated as the difference between plateau and recovery $\dot{\mathrm{V}}_{2}$ multiplied by the time constant of offset.

\section{STATISTICS}

Comparisons between groups was with Student's $t$ test. For comparisons of the constant workload data, we used analysis of variance with post hoc testing where differences were found. Probability $(\mathrm{p})$ values of $<0.05$ were taken to be significant. Results are given as means (SD), with $95 \%$ confidence intervals (CI) for any differences.

\section{Results}

Subject characteristics are shown in table 1 . Peak oxygen consumption was significantly greater in the controls, but the respiratory exchange ratio at peak was the same in each group suggesting similar levels of exertion.

There was no difference between resting and plateau oxygen consumption (table 2), nor for the time constant of onset, but the time constant for offset was longer in the patients than controls. There was no difference in the oxygen deficit between the two groups, but the oxygen debt was slightly greater in the heart failure group.

Although the oxygen consumption during the plateau phase was the same for each group, this was at a higher proportion of peak $\mathrm{V}_{\mathrm{O}_{2}}$ for the patients $(36.7(12.8) \%$ in controls $v 60.1$ (16.0)\% in patients (95\% CI 9.8 to 37.0 ), $\mathrm{p}=0.002)$. As a reflection of the greater metabolic stress, the respiratory exchange ratio was higher during the plateau in patients $(0.90$ $(0.05)$ in controls $v 1.03(0.06)$ in patients (95\% CI 0.08 to 0.18$), \mathrm{p}<0.001)$.

There was no difference in $\dot{\mathrm{V}} \mathrm{CO}_{2}$ during the plateau phase between patients and controls (660 (180) $\mathrm{ml} / \mathrm{min}$ in controls $v 677$ (111) $\mathrm{ml} / \mathrm{min}$ in patients), but ventilation was higher in the patients, at $34.5(4.23) v 26.0$ (4.5) $1 / \mathrm{min}$ $(95 \%$ CI 0.9 to 17.9$), \mathrm{p}=0.05)$. The ventilatory equivalent for $\mathrm{CO}_{2}$ was thus higher in patients $(40.3(4.9)$ v 50.1 (11.0) $1 / 1$ (95\% CI 1.8 to 17.8$), \mathrm{p}<0.01)$.

The time constants for $\dot{\mathrm{V}}_{2}, \dot{\mathrm{V}}_{\mathrm{CO}_{2}}$, and $\dot{\mathrm{V}} \mathrm{E}$ are shown in tables 2 and 3. The time constants for onset were not different between the two groups, but for each of the three, the time constant of offset was greater in the patient group. The time constants $(\tau)$ of onset for $\dot{\mathrm{V}}_{2}, \dot{\mathrm{V}} \mathrm{CO}_{2}$, and $\dot{V}$ E correlated closely with one another, as did the time constants for offset (table 4). $\tau \mathrm{O}_{2}$ onset and $\tau \mathrm{O}_{2}$ offset did not correlate well. The relation between oxygen deficit and oxygen debt is shown in fig 2 . 


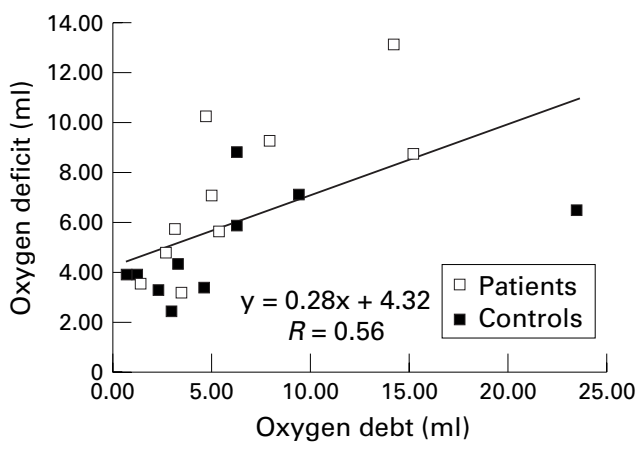

Figure 2 The relation between oxygen deficit and oxygen debt.

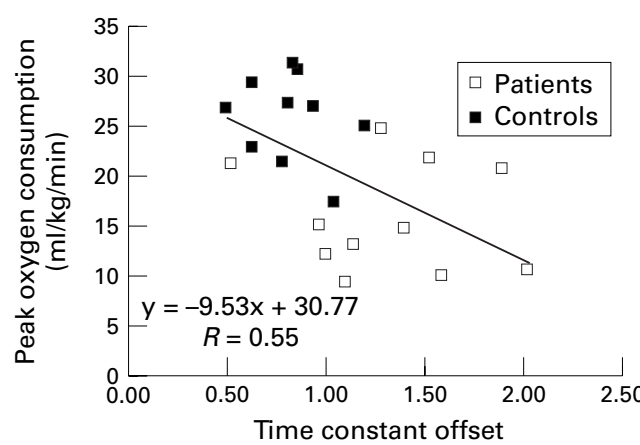

Figure 3 The relation between the time constant of offset at the end of exercise $\left(\tau \mathrm{O}_{2}\right)$ and peak oxygen consumption.

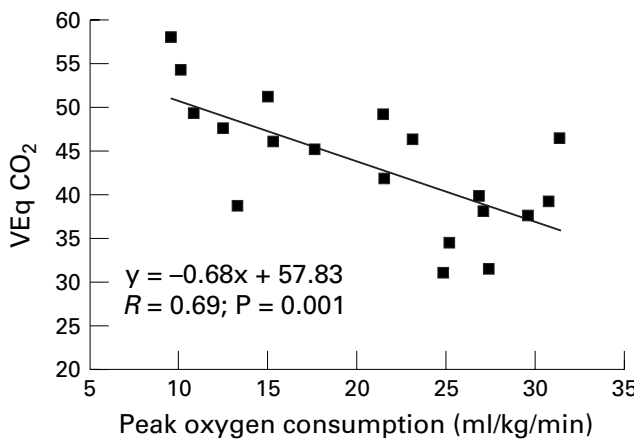

Figure 4. The relation between peak oxygen consumption $\left(\mathrm{V}_{\mathrm{O}_{2}}\right)$ and the ventilatory equivalent for $\mathrm{CO}_{2}\left(\mathrm{VEq} \mathrm{CO}_{2}\right)$ during steady state exercise.

There was a relation between peak $\dot{\mathrm{V}}_{2}$ and $\tau$ $\mathrm{O}_{2}$ offset $(R=0.56, \mathrm{p}<0.001$; fig 3$)$ but not with $\tau \mathrm{O}_{2}$ onset. There was an inverse relation between ventilatory equivalent for $\mathrm{CO}_{2}$ during the plateau phase and peak $\dot{\mathrm{V}}_{2}(R=-0.68$; $\mathrm{p}=0.001$; fig 4 ).

\section{Discussion}

Patients with chronic heart failure experience fatigue and breathlessness on exercise. In the laboratory, exercise capacity has been quantified as peak oxygen consumption during incremental tests. This has the obvious limitation that very few patients actually undertake maximum exercise during day to day life. What may be of more pathophysiological interest is the response to submaximal exercise. The metabolic cost for a given task of everyday life will be the same whether a subject has heart failure or not; we have thus chosen to examine the responses to fixed level low grade exercise.

We have shown that the oxygen consumption at a given load is the same for patients and controls. This is expected in that a given workload must require the same energy expenditure regardless of who performs it. Patients will be exercising at a greater percentage of their maximum capacity. The respiratory exchange ratio, which can be taken as an index of the metabolic cost of exercise, is greater in patients.

We also investigated the possibility that patients may take longer to achieve steady state exercise kinetics than controls, as has been reported previously. ${ }^{3}$ By plotting the oxygen consumption data and counting by hand, Chelimsky-Fallick et al found the oxygen deficit to be increased in heart failure. ${ }^{7}$ Other investigators have reported prolonged time constants of recovery from maximum exercise. $^{56}$

We designed our experiment to examine the dynamics of onset and offset from submaximal steady state exercise. Our hypothesis was that, perhaps as a consequence of abnormal skeletal muscle metabolism, ${ }^{89}$ patients may show delayed recovery from exercise compared with controls and have a greater oxygen debt.

We found no difference between patients and controls at the onset of exercise, but a prolonged recovery time at the end. As a corollary, the oxygen debt was also greater. These abnormalities are related to a reduction in peak exercise capacity, although we measured peak oxygen consumption using treadmill rather than cycle exercise.

We cannot explain why our results for the onset of exercise are not in accordance with other investigators. We were careful to chose a work load that would be below the anaerobic threshold for our patients. Work above the anaerobic threshold results in a progressive increase in $\dot{\mathrm{V}}_{2}$ during steady state exercise, ${ }^{10}$ and thus an overestimate of $\tau$ onset. This may account for the prolonged $\tau$ in some studies. ${ }^{71}$

From the patient's perspective, the time course of recovery may be more important. A given activity requires the same expenditure of effort as for a normal person, but this is at the cost of a prolonged recovery time and an increased oxygen debt. A patient spends a greater portion of the day recovering from exercise, and may not begin the next bout from a position of true recovery, contributing to the sensation of fatigue. We have deliberately selected a group of patients with moderately severe heart failure. It will be interesting to see if the relation between prolonged recovery and exercise capacity holds true for patients with milder disease.

\section{Appendix}

CALCUlation OF TIME CONSTANTS

The increase of any variable to a plateau during stable exercise is described by the monoexponential function:

$$
x(t)=x_{2}-(\delta x) e^{-\left(t-t_{1}\right) / \tau_{\text {on }}}
$$

where $\tau_{\text {on }}$ is the time constant of onset. Similarly, the decrease of that variable from its plateau to its resting state at the end of exercise is described by the monoexponential function

\section{$x(t)=x_{1}+\left(x\left(t_{2}\right)-x_{1}\right) e^{-\left(t-t_{2}\right) / \tau_{\text {off }}}$}


where $\tau_{\text {off }}$ is the time constant of offset. In these formulae, $t$ is time, and $t_{1}$ and $t_{2}$, respectively, the times at which exercise starts and finishes.

The parameters are found by fitting the formulae to the observations on the basis that individual observations are contaminated by white noise of constant standard deviation, $\sigma$, to be determined by the fitting procedure. Briefly, if a realisation of the experiment contains $n$ observations $\left(t_{1}, x_{1}\right), \ldots,\left(t_{\mathrm{n}}, x_{\mathrm{n}}\right)$, then the parameters are found by maximising the likelihood function

$$
\prod_{k=1}^{n} \frac{1}{\sqrt{2 \pi} \sigma} \exp \left[-\frac{\left(x_{k}-x\left(t_{k}\right)\right)^{2}}{2 \sigma^{2}}\right]
$$

or, more conveniently, by minimising the negative log likelihood function

$$
\phi=\frac{1}{2 \sigma^{2}} \sum_{k=1}^{n}\left(x_{k}-x\left(t_{k}\right)\right)^{2}+n \log \sigma+\frac{n}{2} \log (2 \pi)
$$

This minimisation was achieved using the Broyden's method. ${ }^{12}$ The main diagonal of the inverse Hessian of $\phi$ yields the standard errors in the estimation of the parameters.
1 Clark AL, Poole-Wilson PA, Coats AJS. Exercise limitation in chronic heart failure: central role of the periphery. $f \mathrm{Am}$

2 Whipp BJ, Ward SA, Lamarra N, et al. Parameters of ventilatory and gas exchange dynamics during exercise. F Appl Physiol 1982;52:1506-13.

3 Koike A, Hiroe M, Adachi $\mathrm{H}$, et al. Oxygen uptake kinetics are determined by cardiac function at onset of exercise rather than peak exercise in patients with prior myocardial infarction. Circulation 1994;90:2324-32.

4 Riley M, Pórszàsz, Stanford CF, et al. Gas exchange responses to constant work rate in chronic heart failure. $\mathrm{Br}$ Heart f 1994;72:150-5.

5 Cohen-Solal A, Laperche T, Morvan D, et al. Prolonged kinetics of recovery of oxygen consumption after maximal graded exercise in patients with chronic stable heart failure: analysis with gas exchange measurements and NMR spectroscopy. Circulation 1995;91:2924-32.

6 de Groote P, Millaire A, Decoulx E, et al. Kinetics of oxygen consumption during and after exercise in patients with dilated cardiomyopathy. $\mathcal{F}$ Am Coll Cardiol 1996;28:168-75.

7 Chelimsky-Fallick C, Stevenson LW, Lem V, et al. Excessive oxygen deficit during low-level exercise in heart failure. Am f Cardiol 1995;76:799-802.

8 Mancini DM, Coyle E, Coggan A, et al. Contribution of intrinsic skeletal muscle changes to $31 \mathrm{P}$ NMR skeletal muscle abnormalities in patients with chronic heart failure. Circulation 1989;80:1338-46.

9 Sullivan MJ, Green HJ, Cobb FR. Altered skeletal muscle metabolic response to exercise in chronic heart failure: relation to skeletal muscle aerobic enzyme activity. Circulation 1991;84:1597-607.

10 Casaburi R, Barstow TJ, Robinson T, et al. Influence of work rate on ventilatory and gas exchange kinetics. $7 \mathrm{Appl}$ Physiol 1989;67:547-55.

11 Cross AM, Higginbotham MB. Oxygen deficit during exercise testing in heart failure-relation to submaximal
exercise tolerance. Chest $1995 ; \mathbf{1 0 7}: 904-5$.

12 Broyden CG. Quasi-Newton methods and their application to function minimisation. Math Comput 1967;21:368-81. 